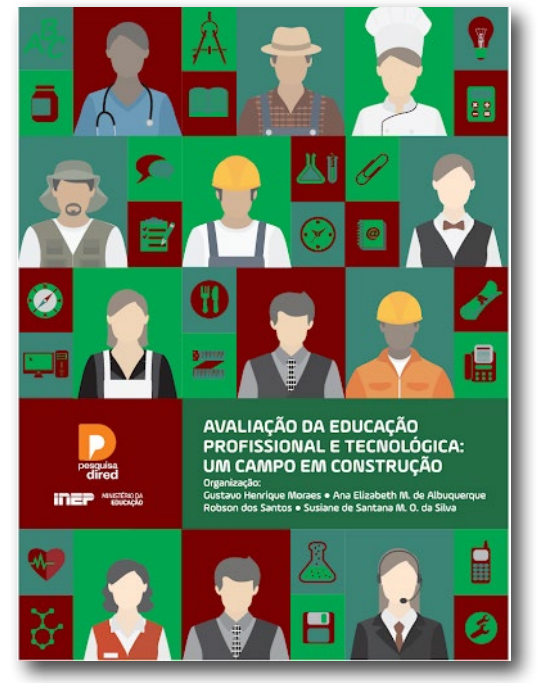

\section{RESENHA DA OBRA}

\author{
MORAES, G. H.; ALBUQUERQUE, A. E. M.; SANTOS, \\ R.; SILVA, S. S. M. O. (org.). Avaliação da educação \\ profissional e tecnológica: um campo em construção. \\ Brasília: Instituto Nacional de Estudos \\ e Pesquisas Educacionais Anísio Teixeira, 2020.
}

\title{
Saberes do trabalho e avaliação da educação profissional e tecnológica
}

Curso de capacitação de chocolateiros. A escola o indica como experiência que devo observar em meu estudo sobre atuação e formação de professores de educação profissional. A atividade do dia é a preparação de quatro diferentes tipos de bombons. Dezoito alunos, todos adultos, a maioria constituída por mulheres. Começamos numa sala de aula comum, onde a professora anuncia o que será feito no dia e divide a turma em quatro equipes de produção. Isso não dura mais que dez minutos. Saímos da sala de aula e vamos para um ambiente que a escola chama de planta de produção artesanal de chocolate, uma oficina.

A planta de produção é um ambiente amplo, com tudo que é preciso para que se possa produzir chocolate artesanalmente. Cada equipe busca insumos e utensílios necessários ao bombom que vai produzir, dirige-se a uma bancada com tampo de granito, derrete o chocolate num forno, traz a massa derretida para a bancada e começa a desenvolver o processo de produção. A professora observa e acompanha o trabalho das equipes, e a cada momento crítico do processo solicita que os alunos façam uma pausa. Ela vai para uma das bancadas, convida as demais equipes para se aproximarem. Analisa o que foi feito. Mostra possíveis desvios no processo. Faz, se necessária, uma demonstração para corrigir rumos. Repete isso em cada uma das quatro equipes e orienta os alunos a prosseguirem para a fase seguinte de produção. As intervenções docentes voltam a acontecer em outras fases críticas até o momento em que todas as equipes tenham produzido o bombom sob sua responsabilidade.

A professora não tinha formação universitária. Era uma jovem técnica com bastante experiência no campo de trabalho em que atuava como docente. Utilizava 
abordagem de avaliação bastante sofisticada. Fez algo que não consegui perceber à primeira vista. No começo pensei que ela estava utilizando uma abordagem metodológica centrada na obra em elaboração. Engano meu. Ela não estava apenas ensinando. Estava também avaliando. E utilizava uma abordagem avaliativa que autores da área chamam de avaliação formativa. Os alunos estavam num processo de aprendizagem dividido em fases. E cada fase podia ser avaliada para orientar a aprendizagem e evitar possíveis enganos que apareceriam nas fases seguintes. Eu nunca tinha visto tal uso da avaliação formativa. Mas, ela estava acontecendo ali. A professora, porém, jamais ouvira falar no termo técnico que designa a forma de avaliar que estava utilizando.

Inicio esta resenha com um caso bem simples, quase simplório. E faço isso por um motivo: o trabalho é uma atividade cujos desdobramentos epistemológicos sugerem decisões metodológicas e avaliativas muito próprias em educação, mas bastante distantes dos modos habituais de educar nas escolas. Tais sugestões não costumam estar em livros de didática. Elas, porém, são percebidas intuitivamente por docentes que conhecem bem o saber do trabalho que ensinam. A especificidade dos saberes do trabalho, por outro lado, pode provocar tensões quando se insiste em utilizar categorias gestadas historicamente nas escolas para avaliar formação profissional em todos os níveis. Isso pode ser visto muitas vezes em Avaliação da educação profissional e tecnológica: um campo em construção.

É obra necessária e oportuna que aborda diversas dimensões de avaliação da e na educação profissional e tecnológica no Brasil. Os capítulos do livro foram elaborados por um grande grupo de educadores, quase todos com experiência em processos avaliativos no campo da formação profissional. Não é possível, numa única resenha, fazer justiça a todos os conteúdos que aparecem na publicação. Talvez valesse escrever três ou quatro resenhas temáticas sobre conjuntos de capítulos da obra. Outra possibilidade é a de ressaltar alguns aspectos que aparecem no livro e que merecem destaque no campo da avaliação da formação profissional. Escolhi este último caminho, correndo o risco de não oferecer uma visão articulada da obra inteira.

\section{Epistemologia do fazer}

Uma grande preocupação epistemológica aparece em quase toda a obra, seja em discussões sobre fundamentações, seja na concepção de instrumentos utilizados nos diversos níveis avaliativos. Isso, de certa maneira, é uma novidade em estudos sobre formação profissional. Há autores, como Merrill (1983), que associam tipos de conhecimentos com decisões metodológicas. Mas eles fazem isso sem aprofundar discussões sobre epistemologia e educação. A obra em foco avança a discussão, apontando para rumos que podem deixar mais clara a especificidade da educação associada ao trabalho, assim como clarear a tensão existente entre duas diferentes propostas educacionais que nasceram em ambientes completamente distintos, a escola e a oficina. 
A ação, o fazer, a técnica, reflete um conhecimento que não costuma ser considerado pelos educadores. Para esses últimos, a ideia de que fazer é uma categoria específica de saber despertará o mesmo espanto que Jerome Bruner sentiu quando Sylvia Scribner Ihe apresentou plano de pesquisa para estudar o saber decorrente do fazer dos leiteiros de Nova York (BRUNER, 1999).

O fazer é visto como uma atividade mecânica que decorre de saberes que a precedem. De certa forma, a velha epistemologia ainda reflete a divisão entre mente e corpo do mecanicismo sugerido por Descartes (JONHSON, 2007). Isso está muito presente nos pares antitéticos que vemos frequentemente em textos e falas de educadores: teoria e prática, mente e corpo, conhecimento e habilidade. A obra em análise propõe a necessidade de superar abordagens epistemológicas que ignoram conhecimentos que não possam ser representados por meio de proposições. O primeiro capítulo examina essa questão recorrendo a diversos autores que vêm insistindo na necessidade de se considerar o saber do fazer como categoria de conhecimento com status próprio. Os autores examinados no livro não constituem uma escola única de pensamento. Mas caminham no mesmo rumo. Os delineamentos de uma epistemologia que reconheça os saberes intrínsecos do trabalho estão se desenvolvendo com base em várias fontes. $O$ que há de comum entre todas elas é o reconhecimento de que a ação, a atividade, o fazer, é uma expressão de conhecimento humano. Isso coloca vários desafios em termos de avaliação. Instrumentos e práticas avaliativas em educação estão voltados para o conhecimento proposicional, ou "intelectual", como diz um autor citado e criticado no livro em análise (p. 35). Essa é uma visão que reduz a técnica a um fazer em que estão ausentes dimensões cognitivas. Em outros capítulos, ao examinar possibilidades de avaliação do saber do trabalho, há aparente aceitação da divisão entre teoria e prática, em propostas de construção de provas práticas. Vou examinar tal questão mais à frente, porém, considerando a discussão que se faz sobre o saber do fazer no primeiro capítulo, quero assinalar desde já que o termo "prova prática" reflete aceitação de uma epistemologia que não valoriza o saber do trabalho.

A obra propõe uma discussão interessante sobre técnica que, incidentalmente, lembrou-me conversa recente que tive com educadores sobre uma proposta de formação profissional de jovens. Tal proposta considerava que a abordagem de conteúdos humanísticos era distinta da abordagem dos conteúdos técnicos. Isso reflete pensamento hegemônico de que a técnica é algo alheio a sentimentos e valores. Na obra em análise, assinala-se, com base no filósofo Álvaro Vieira Pinto (p. 38 e ss.), que os homens constroem sua existência por meio da técnica. Nada mais humano, portanto, que essa forma de agir no mundo. Uma das consequências de entender a técnica como algo apartado da ontologia do ser humano é o engano frequente de dissociar o fazer do trabalho das dimensões epistemológicas, éticas e estéticas. Isso resulta em ignorância de que o saber do trabalho inclui necessariamente o fazer bem feito. $O$ saber do trabalho, assim como a estética e a ética da profissão, não é algo que se agrega ao fazer. Saber, ética e estética são inerentes ao fazer. 
Há outro aspecto que perpassa a obra, o de considerar que o fazer não é um ato mecânico, resultante de um treino para amoldar gestos e movimentos exigidos pelo trabalho. $O$ fazer exige atividades mentais para representar a ação e guiá-la. Mais uma vez, é preciso ressaltar que o mental não se separa da execução, mas é dela parte integrante.

A preocupação com aspectos epistemológicos tem dois alvos importantes na obra resenhada: o que avaliar em formação profissional; como avaliar os saberes do fazer. Vou recorrer ao exemplo que utilizei para iniciar esta resenha, a fim de comentar a discussão sobre saberes do trabalho desenvolvida pela obra, mesmo correndo o risco de simplificar em demasia o pensamento dos autores. O que avaliar no caso dos bombons? Certamente não há um discurso bem articulado sobre esse saber em confeitaria. Para avaliar o fazer/saber precisamos de evidências acerca das capacidades de produzir obras próprias de uma profissão. Poderíamos, por exemplo, solicitar ao avaliado que fizesse um bombom trufado. E, no final do processo, apreciar a obra para saber se o confeiteiro desenvolveu o conhecimento do fazer. Isso, porém, não é tudo. Desafios de produção precisam estar atentos para os processos cognitivos do fazer. E esses processos não são uma teoria que precede a prática, mas um conhecimento entranhado na ação. Há ainda outros aspectos a considerar. Os autores do livro em foco apontam que o saber do fazer é situado. Ele acontece num espaço (numa situação) em que faz sentido. Além disso, o saber do trabalho requer mediação de ferramentas e insumos como uma dimensão do saber fazer. E mais, requer adesão a certos valores do trabalho. Que proposta avaliativa é capaz de levar em conta todos esses aspectos? Esse é um desafio que ainda precisa de boas respostas. A obra mostra diversas tentativas em tal direção, mas o velho modelo de uma educação escolar continua a predominar e limita esforços avaliativos do saber fazer.

Os alunos do curso de chocolateiro trabalhavam em equipe. O que se avaliava não era o desempenho individual de cada um deles, mas o fazer do grupo responsável por certo tipo de bombom. Mais uma vez estamos diante de um aspecto situacional que a obra resenhada aborda ao considerar uma epistemologia do fazer. A leitura situacional do saber do trabalho precisa considerar dimensões cooperativas da produção de obras, aspecto que vem sendo ressaltado por pesquisadores que analisam a emergência de saberes em comunidades e prática (WENGER, 1998). Isso coloca um desafio que o livro não chega a explicitar, mas que é congruente com as análises epistemológicas que desenvolve. Cabe sempre uma avaliação individualista do fazersaber, ou alguns eventos de avaliação precisam considerar atividades desenvolvidas cooperativamente? Avanço aqui para uma questão que não é abordada explicitamente pelos autores. Ela, porém, é congruente com a epistemologia do fazer. Observo incidentalmente que a produção de bombons artesanais pode ocorrer como atividade individual, mas ela é muito mais comum como atividade desenvolvida em cooperação. Não se trata aqui apenas de saber se o trabalhador é capaz de trabalhar com os outros, na linha do que vem sendo chamado de soft skills. O que possivelmente precisa ser observado na avaliação é o uso de um saber situado, em que o trabalho ocorre 
cooperativamente. Cooperar, portanto, pode ser uma demanda muito concreta do saber fazer. E para avaliá-lo não bastam testes e/ou provas individuais de execução.

Saio da planta de produção artesanal de chocolates e vou para uma oficina de soldagem onde observei um instrutor, sem formação universitária, utilizando material que listava os critérios mais importantes que deveriam ser observados na solda executada (rubrica) para avaliar seus alunos. Na obra resenhada, proposta de avaliação semelhante a esta aparece numa narrativa sobre curso técnico para formação de padeiros. Perguntada como avaliava seus alunos, a professora do curso responde: "pelo pão" (p. 53). Não há registro de que esta docente utilizasse rubricas avaliativas. Mas tal instrumento caberia na avaliação utilizada por ela. Não importa muito aqui se rubricas são ou não utilizadas no caso. O que importa é uma resposta que surpreendeu educadores que não estavam muito próximos do fazer/saber na padaria e talvez esperassem que a docente sugerisse verificação de aprendizagem por meio de provas tradicionais no ambiente escolar (GRUBER; ALLAIN; WOLLINGER, 2019).

Ressaltei nos exemplos examinados - solda e bombom - a avaliação voltada para produto. Mas, como se verifica em diversas propostas de avalição do fazer na obra, é preciso avaliar como o processo técnico é utilizado pelo aluno. E observações sobre processo técnico abrangem o uso de equipamento de proteção individual (EPI), gestos, utilização de ferramentas, leitura e interpretação de desenhos e diagramas, registro de resultados parciais etc. Em instrumentos descritos em alguns capítulos é possível ver que a avaliação de execução pode abranger verificação de correção de processos e resultado final concretizado no produto. A verificação de aprendizagem centrada em produtos é muito exigente, se considerarmos avaliações de larga escala, uma vez que o saber que resulta em execução não pode ser aferido por meio de proposições características dos testes convencionais, em que se usa apenas papel e lápis. É preciso que os avaliadores observem o fazer. Capítulos da obra que abordam instrumentação do saber do fazer reconhecem isso. E, talvez por essa razão, os instrumentos privilegiam a avaliação de processos e ainda não oferecem boas respostas para a avaliação voltada para o produto.

Há diversos capítulos com propostas de avaliação que consideram a especificidade do saber do fazer. Os autores que escrevem sobre isso na obra acentuam a necessidade de bem definir o objeto da avaliação, de escolher formas de instrumentação que garantam resultados confiáveis, de contar com tratamentos estatísticos capazes de assegurar validade e confiabilidade nos resultados. Recomendo análise de cada um desses capítulos para ver algumas das direções possíveis em avaliações específicas da formação profissional.

\section{Instrumentação da avaliação}

Talvez o termo instrumentação da avaliação não seja o mais adequado para os diversos capítulos que apresentam sugestões de como avaliar resultados da formação profissional em diferentes níveis. Um desses níveis é aquele cujos resultados oferecem indicações sobre qualidade da educação. Geralmente essa aferição de re- 
sultados acontece em avalições de larga escala. Um exemplo de avaliação de larga escala é o Exame Nacional do Ensino Médio (ENEM). Cito esse exemplo porque ele é o mais conhecido, com grande visibilidade nos meios de comunicação. O ENEM, com o tempo, converteu-se num evento avaliativo muito confiável, sobretudo por causa da sofisticação estatística da apuração de resultados, com uso da Teoria da Resposta ao Item (TRI). Em várias partes da obra, sugere-se que a avaliação em larga escala para educação profissional tenha a mesma sofisticação estatística e utilize a TRI. Essa é uma orientação interessante, mas parece que o saber do fazer não poderá receber o mesmo tratamento que resulta em testes como os utilizados pelo ENEM. E neste último, na avaliação de um aspecto importante para qualidade da educação, a verificação da capacidade de se comunicar por escrito (redação), não há uso da TRI. A obra aborda essa questão com algumas propostas de instrumentação. Uma delas é um ensaio de avaliação do fazer que realça a dimensão psicomotora, em oposição às dimensões cognitivas e afetivas nos termos da classificação proposta por Benjamin Bloom. E tal tentativa baseou-se em definições muito sofisticadas do que avaliar e das bases estatísticas para fundamentar análise de resultados. Trata-se de uma proposta de avalição prática (p. 119). Minha leitura dessa terminologia indica que a proposta não se desvincula inteiramente do par antitético teoria e prática. Ela se vale de concepções de situações-problema para desenhar desafios avaliativos que possam verificar diversos traços de saber presentes na atividade do avaliado, na medida em que este age para elaborar o produto esperado. É uma tentativa que busca identificar aspectos de execução de técnicas e, a partir deles, fazer inferências sobre o domínio do fazer. Cabe reparar que o instrumento proposto não é exclusivamente restrito ao campo psicomotor. Na descrição sumária para cada nível de desempenho aparecem aspectos que nada têm de psicomotor; uso de EPI, por exemplo.

Como já assinalei, a obra utiliza o termo "prova prática" em vários capítulos, denunciando dificuldade para superar a referência aos pares antitéticos criticados no próprio livro. Essa dificuldade já foi percebida pelo filósofo Mark Johnson (2007), que propõe uma epistemologia que não separa mente e corpo. Johnson aponta que nos falta, porém, um vocabulário adequado para designar o saber humano integral. Mas no caso das provas práticas, creio que é possível uma saída. É melhor chamá-las de provas de execução. E as dificuldades para superar uma epistemologia tradicional, que privilegia o que podemos chamar - talvez impropriamente - de intelectual, continuam. Em vários capítulos que abordam instrumentos constitutivos de provas de execução predomina a separação entre conhecimento e habilidade. Um e outra não são definidos. Porém, o pressuposto é o de que o termo conhecimento se refere ao saber declarativo ou proposicional. Refere-se ao saber que predomina nos ambientes escolares. Analogamente, outro pressuposto é o de que o termo habilidade diz respeito a capacidades de fazer desprovidas de status epistemológico próprio.

Testes e provas tradicionais estão vinculados a uma epistemologia que privilegia o saber abstrato que pode ser representado por meio de proposições. Isso influen- 
ciou todos os modelos avaliativos que conhecemos na escola. Além disso, pesquisas em avaliação são influenciadas pelos modelos escolares de como aferir aprendizagem. Daí o espanto de educadores da academia com a declaração da professora do curso de formação de padeiros de que ela avalia seus alunos pelo pão. A obra propõe, em diversos capítulos, que a avaliação de execução (provas "práticas"), que os instrumentos sejam construídos tendo em conta competências, habilidades e objetos de conhecimento, refletindo uma epistemologia que utiliza o par antitético teoria e prática. Nos exemplos fornecidos pelos autores há diversos casos de instrumentos que foram testados com sucesso e podem ser considerados avanços no campo da avaliação do saber fazer. Mas esse esforço está contaminado por modelos avaliativos intelectualistas e ainda não assumiu radicalmente uma epistemologia que considere o fazer, a técnica, o knowing how (RYLE, 1984) como conhecimento per se. Talvez a saída seja adotar uma avaliação centrada no produto, como faz a professora do curso técnico em panificação.

Nos exemplos que aparecem no livro, o detalhamento do que deve ser observado em avaliações de execução lembra descritores de tarefa. E em tais descritores é possível perceber elementos descritivos de produto (ou serviço) e de processos de execução. Mas quase sempre os componentes do processo de execução são convertidos em itens de testes numa transposição que escolariza saberes que integram o fazer. Isso, a meu ver, converte indevidamente conhecimento de processos em conhecimento proposicional. Essa conversão é resultado de uma solução ainda incapaz de encontrar meios para apreciar avaliativamente o fazer.

\section{O nó da qualificação profissional}

Quase todos os capítulos do livro elegem como modalidade referencial de análise os cursos técnicos de nível médio. E na análise da estrutura do ensino voltado para a formação profissional merece também destaque o ensino superior, embora este tenha diversos problemas de identidade, pois engloba não só cursos de educação tecnológica, bacharelados e licenciaturas, se estes últimos estiverem alojados em endereço de instituição de EPT. A prima pobre da educação profissional e tecnológica é a qualificação profissional, ultimamente classificada sob o amplo guarda-chuva da FIC (Formação Inicial e Continuada). Conceitualmente, qualificação profissional é uma modalidade de ensino sem definição clara. Ela é entendida, quase sempre, como educação profissional que se faz à margem do sistema de ensino. Além disso, nem sempre fica bem caracterizada em sua relação com possiveis destinos profissionais. Essas dúvidas acontecem mais nos meios educacionais que conseguem ver a formação profissional apenas como uma atividade de educação escolar. Mas a qualificação profissional acontece, para muitas ocupações, sem vinculações com o sistema escolar. E como nas propostas de avaliação predominam abordagens moldadas pelas práticas de educação formal, há grandes dificuldades para obter números precisos sobre qualificação profissional e a avaliação de sua qualidade no país. O reconhecimento dessa limitação estatística aparece em vários capítulos do livro. 
Na totalização de números sobre formação profissional, FIC aparece como uma categoria única, incluindo qualificação profissional e muitas outras atividades que não são propriamente preparação para uma ocupação. O curso de chocolateiro, que acompanhei numa pesquisa, não é de qualificação profissional. É um programa de curta duração, voltado para gente que quer aprender técnicas de produção de chocolate artesanal para ampliar seus horizontes profissionais de confeitaria. Ele se encontra numa categoria de difícil definição, embora seja uma atividade claramente de formação profissional. Muitas outras atividades podem ser consideradas sob o amplo guarda-chuva da FIC, carecendo de uma conceituação clara. Listo apenas para ilustração os seguintes programas: inglês para garçons, arranjos florais, cozinha indiana, redação para secretárias. Os exemplos que elenquei podem ser classificados como educação continuada (outra categoria muito ampla e imprecisa). Um nó que vejo no caso é o de que esses programas se misturam indistintamente com qualificação profissional dentro do amplo espectro abrangido elo termo FIC.

Qualificação profissional é uma atividade que tem por fim capacitar pessoas para o exercício de uma ocupação. Assim definida, ela é equivalente ao que se pretende com um curso técnico de nível médio, ou mesmo com um curso superior de tecnologia, ou ainda com um bacharelado. Por razões de status, algumas qualificações profissionais não são desenvolvidas no nível médio ou superior. Entre elas, posso citar as de formação de cabeleireiros, pedreiros, carpinteiros, encanadores. Caso interessante é o do fisioterapeuta. A formação desse profissional começou num curso de qualificação no âmbito do ensino livre, passou depois a acontecer num curso técnico de nível médio, converteu-se posteriormente num curso superior de curta duração, para chegar finalmente a um bacharelado (MARQUES; SANCHES, 1994). Boa parte das atividades de qualificação profissional não experimenta a evolução acontecida com o fisioterapeuta, continua a existir como atividade educacional desvinculada do sistema formal de ensino. A obra em foco mostra que a qualificação profissional não recebe atenção suficiente, quer seja em apurações dos grandes números de caráter censitário, quer seja em termos de propostas de avaliação de larga escala, ou em termos de verificação da aprendizagem no dia a dia.

O livro assinala outras dificuldades no campo do ensino técnico e tecnológico. No caso do primeiro, a apuração de época de matrícula para o ensino médio nem sempre coincide com as formas de ofertas dos cursos técnicos. Isso resulta em apuração equivocada dos números (de turmas, de alunos etc.). No caso do segundo, a apuração dos números sobrepõe-se aos registros sobre o cômputo geral do ensino superior. Isso ainda é mais problemático no caso da qualificação profissional, atividade que quase sempre acontece inteiramente fora dos tradicionais calendários escolares.

Um dos capítulos do livro aborda os programas emergenciais de capacitação profissional como o PIPMO (Programa Intensivo de Preparação de Mão de Obra) e o PRONATEC (Programa Nacional de Acesso ao Ensino Técnico e Emprego). Esses programas foram planejados para oferecer formação profissional básica atenden- 
do necessidades mais imediatas dos trabalhadores, sobretudo os menos escolarizados. Por razões políticas e de premência de necessidade de capacitação profissional, tais programas costumam durar mais tempo que o planejado inicialmente. E não há uma avaliação mais consistente do impacto que eles têm na estrutura geral da EPT. Além disso, não há caracterização segura das modalidades de oferta em tais programas. Neles, aparece mais uma vez uma concepção muito difusa do que é qualificação profissional.

O caso da qualificação profissional reflete, no nível do fazer cotidiano da educação, a necessidade de classificar com clareza todas as modalidades de formação profissional. Reflete também certo descuido dos educadores para considerar atividades de capacitação profissional voltadas para profissões com baixo status social.

Há muitas ocupações cujo grau de complexidade requer um tempo longo de formação, quer seja em organizações não escolares voltadas para o ensino, quer seja em ambientes de trabalho. Por outro lado, a divisão do trabalho, assim como simplificações de algumas profissões com o avanço do trabalho morto, fez surgir no horizonte ocupacional trabalho semiqualificado cujas exigências em termos de formação não são muito grandes. Quando ingressei no SENAC de São Paulo em 1973, cursos rápidos, para formar trabalhadores semiqualificados eram chamados de iniciação profissional, em clara associação com uma capacitação para trabalho semiqualificado. Há, no caso, necessidade de mais estudos para estabelecer com clareza o que hoje é englobado de modo muito impreciso pelo rótulo FIC. E nesse esforço de caracterização será preciso definir bem o que pode ser entendido por qualificação profissional, independentemente de níveis de escolarização. A obra discute essa questão, mas a meu ver não avança na direção de definição de qualificação profissional a partir de saberes do trabalho e de como a capacitação profissional ocorre sem as amarras de modelos escolares.

Há um detalhe que merece atenção particular. A formação profissional desenvolvida de acordo com o estatuto da aprendizagem, uma modalidade de qualificação profissional que articula trabalho na empresa com educação em agências educacionais, não aparece na obra, mesmo nos capítulos que consideram as atividades dos Serviços Nacionais de Aprendizagem. Essa é uma ausência que merece reparo, pois a aprendizagem passou, em alguns países, por profundas reformas para que voltasse a desempenhar importante papel na capacitação dos trabalhadores. E embora não tenham ocorrido reformas semelhantes no Brasil, há no país número bastante expressivo de aprendizes.

\section{0 desafio continua}

Avaliação da educação profissional e tecnológica: um campo em construção é um grande avanço em termos de análises e propostas para a avaliação da capacitação dos trabalhadores. No livro há registros importantes quanto à instrumentação da avaliação do fazer, propostas de avaliação de larga escala na área, acompanha- 
mento de egressos, avaliação de cursos e programas, avaliação institucional. Não foi possível, nesta resenha, abordar todos esses tópicos. Dei preferência a análises sobre as questões epistemológicas relativas ao saber do trabalho e seus desdobramentos no campo da avaliação. O livro avança muito na direção de modos de ver o conhecimento que reconheçam o status epistemológico do fazer. Mas o desafio continua, pois os autores não escaparam inteiramente dos modelos escolares em suas tentativas de sugerir caminhos específicos de avaliação para a formação profissional. Na leitura da obra, selecionei diversos trechos que mostram que ainda predominam modelos escolares e epistemologia que não conseguem categorizar o fazer como conhecimento. Esse é um problema que, segundo Johnson (2007), não conseguimos resolver imediatamente em termos de conceituação. A velha epistemologia, voltada exclusivamente para o saber proposicional (a teoria), ainda domina nossa linguagem sobre conhecimento. Para mostrar isso, anotei diversos trechos da obra que podem ser entendidos como declarações reveladoras do predomínio da velha epistemologia. Eis aqui uma pequena mostra de tais trechos:

A prova prática permite avaliar conjuntamente competências teóricas dos estudantes e suas habilidades práticas [...] (p. 106).

[...] devido à natureza cognitiva da matriz de referência utilizada (construto), os especialistas foram convidados a avaliar cada uma das evidências e descrevê-las de acordo com o domínio psicomotor mobilizado [...] (p. 129).

[...] consolida-se a necessidade de que os conhecimentos, as habilidades e as competências, bem como o aprendizado do saber fazer e a capacidade de empregar as técnicas, os aspectos intrínsecos e diferenciados da educação profissional passem a contar com formas de avaliação que respondam a tais particularidades (p. 244).

"A ação profissional deve estar assentada sobre sólidos conhecimentos científicos e tecnológicos, de sorte que o trabalhador tenha compreensão cada vez maior do processo tecnológico no qual está envolvido, com crescente grau de autonomia intelectual". Portanto, não se trata de um curso de treinamento para um posto de trabalho (p. 316).

Anotei também algumas considerações que revelam dificuldades para situar o fazer (knowing how) como uma dimensão específica e autônoma de conhecimento. Recomenda-se, por exemplo, utilizar prova prática para complementar avaliação de conhecimentos. Fala-se em mensurar habilidade, competências e conhecimentos. Mostra-se que a matriz de referência deve definir perfil de competências que dependem de conjunto de habilidades e conhecimentos. Emprega-se o termo habilidade em sentidos bastante diferentes; um deles me chamou a atenção, o de considerar capacidade de responder itens de testes de múltipla escolha como habilidade. Outro uso do termo habilidade aparece em matrizes de referências como declarações que nos velhos tempos chamávamos de objetivos operacionais ou descritores de desempenhos esperados. E o termo habilidade aparece na obra com outros dignificados, mas sempre como algo distinto de conhecimento. Essas 
ocorrências mostram que uma epistemologia que categoriza o fazer como saber com status próprio ainda é um grande desafio, mesmo para educadores que a aceitam.

\section{Avanços evidentes}

Apontei nesta resenha alguns limites da obra. Mas os considero inteiramente aceitáveis, pois o livro apresenta avanços significativos no campo da avaliação da educação voltada para o trabalho. Esses avanços incluem sinalizações de como é possível adotar uma epistemologia que dê o devido destaque ao saber do trabalho, e iniciativas que mostram caminhos de como construir instrumentos de avaliação apropriados para verificar aprendizagens do saber fazer. A obra é, sobretudo, uma iniciativa que abre caminhos importantes para que tenhamos no país uma educação profissional e tecnológica de qualidade. Está em construção. Merece ser continuada.

\section{Referências}

BRUNER, J. The Culture of Education. Cambridge: Harvard University Press, 1996.

GRUBER, C., ALLAIN, O. e WOLLINGER, P. Didática Profissional: Princípios e referências para a Educação Profissional. Florianópolis: Publicações do IFSC, 2019.

JOHNSON, M. The Meaning of the Body: Aesthetics of human understanding. Chicago: The University of Chicago Press, 2007.

MARQUES, A. e SANCHES, E. Origem e evolução da fisioterapia: Aspectos históricos e legais. Rev. Fisioter, Uni., São Paulo, v. 1, n. 11, p. 5-10, 1994.

MERRILL, M. D. Component Display Theory. In REIGELUTH, C. M. (ed.). Instructional Theories and Models. Hillsdale, N.J.:Lawrence Erlbaum, 1983.

MORAES, G. H.; ALBUQUERQUE, A. E. M.; SANTOS, R.; SILVA, S. S. M. O. (org.). Avaliação da Educação Profissional e Tecnológica: Um campo em construção. Brasília: Instituto Nacional de Estudos e Pesquisas Educacionais Anísio Teixeira, 2020.

RYLE, G. The Conept of Mind. Chicago: The University of Chicago Press, 1994. WENGER, E. Communities of Practice: Learning, meaning, and identity. Cambridge: Cambridge University Press, 1998.

Jarbas Novelino Barato. Professor. Doutor em Educação pela Universidade Estadual de Campinas (Unicamp). Mestre em Tecnologia Educacional pela San Diego State University (SDSU). E-mail: jarbas.barato@gmail.com 